\title{
NOVA ESPÉCIE DE ACAMPSIS WESMAEL (HYMENOPTERA, BRACONIDAE, SIGALPHINAE) DO BRASIL
}

\author{
Angélica Maria Penteado-Dias ${ }^{2}$
}

\begin{abstract}
A NEW SPECIES OF ACAMPSIS Wesmael (Hymenoptera, BraConidae, SigalphinaE) From Brazil. Acampsis brasiliensis, sp.n. is described from Brazil. This is the first report of this genus to New World.

KEY WORDS. Hymenoptera, Braconidae, Acampsis, systematics
\end{abstract}

Acampsis Wesmael, 1835 é um dos menores gêneros de Braconidae e contém, além da espécie tipo A. alternipes (Nees, 1813), duas outras espécies descritas por CHEN \& HE (1992) da China: A. chinensis e A. hunanensis e três descritas por ACHTERBERG \& AUSTIN (1992) para o Japão e Coréia: A. nigrifemur, A. granulatus e A. brevis.

Com base nas chaves de identificação e descrições de espécies apresentadas por CHEN \& HE (1992) e ACHTERBERG \& AUSTIN (1992) foi identificada uma nova espécie para o Brasil que é aqui descrita e ilustrada. A legenda utilizada para as células e nervuras da asa anterior segue ACHTERBERG (1993).

Trata-se da primeira citação de uma espécie desse gênero para o Novo Mundo.

\section{Acampsis brasiliensis, sp.n.}

Fig. 1

Diagnose. Fêmea com fêmur posterior avermelhado; antena com 56 artículos; comprimento da terceira abcissa do radio 1,5 vezes o comprimento da segunda (Fig. 1); comprimento do primeiro tergito duas vezes a largura apical; asa anterior com mais de $8,0 \mathrm{~mm}$ de comprimento.

Holótipo fêmea. Coloração geral amarelada; cabeça preta; labro amarelado; mandíbulas amareladas com ápice enegrecido; palpos amarelados com exceção dos três segmentos apicais dos maxilares e o apical dos labiais que são castanho claro; antenas pretas. Tórax de cor geral amarela com protórax, grande parte da mesopleura, mesosterno, mesoscuto pretos; escutelo amarelo com manchas pretas; propódeo amarelado; pernas anteriores e médias amarelas com exceção do ápice da tíbia e último segmento tarsal que são pretos; pernas posteriores de cor avermelhada, com segmentos tarsais amarelados, manchados de preto na linha mediana dorsal. Primei-

1) Trabalho financiado pelo CNPq.

2) Departamento de Ecologia e Biologia Evolutiva, Universidade Federal de São Carlos. Caixa Postal 676, 13565-905 São Carlos, São Paulo, Brasil. 
ro tergito abdominal amarelado; segundo e terceiro de cor predominantemente avermelhada; os $2 / 3$ apicais do terceiro tergito são negros bem como os demais tergitos sob ele. Asas hialinas com o terço apical escurecido; nervuras castanho escuro com exceção daquelas abaixo do estigma e a anal que são, como ele, amareladas.

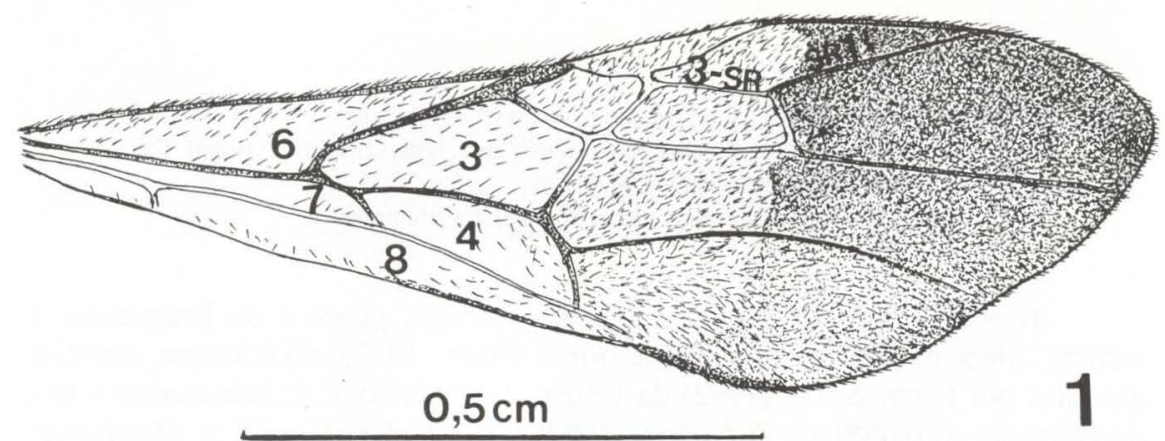

Fig. 1. Acampsis brasiliensis, sp.n., asa anterior. (3) Célula discal; (4) célula subdiscal; (6) célula basal; (7) célula subbasal; (8) célula plical; (3-SR) segunda abcissa do rádio; (SR1) terceira abcissa do rádio.

Pilosidade geral do corpo dourada e bem desenvolvida. Asas anteriores com áreas glabras nas células basal, subbasal, primeira discal, subdiscal e plical (Fig. 1).

Antenas com 56 artículos; carena occipital ausente médio dorsalmente; face pontuada, clípeo pouco deprimido; "pronope" dorsal e laterais fundos e grandes; mesopleura grosseiramente crenulada anteriormente; sulco precoxal bem esculturado; notáulices estreitas, bem marcadas e distintamente crenuladas; carenas medianas do primeiro tergito divergentes para o ápice.

Comprimento do corpo: $10,0 \mathrm{~mm}$; comprimento das asas anteriores: $10,5 \mathrm{~mm}$; comprimento das bainhas do ovipositor menor que o comprimento do terceiro tergito; largura máxima do clípeo 0,8 vezes a largura mínima da face; comprimento das antenas igual ao comprimento das asas anteriores; terceira abcissa do radio 1,5 vezes o comprimento da segunda; comprimento do primeiro tergito 2,0 vezes a largura apical.

Etimologia. Nome alusivo ao país de procedência.

Holótipo fêmea. BrasiL, Amazonas: Tefé (443’24"S-66²0'06"W), 16-IX1994, Buhrnheim et al. leg. Depositado na coleção entomológica do Departamento de Biologia (Laboratório de Zoologia) da Universidade do Amazonas (UFA, Manaus, Amazonas).

AGRADECIMENTOS. A autora agradece ao Departamento de Biologia (Laboratório de Zoologia) da Universidade do Amazonas pelo empréstimo do material. 


\section{REFERÊNCIAS BIBLIOGRÁFICAS}

ACHTERBERG, C. VAN. 1993. Illustrated key to the subfamilies of the Braconidae (Hymenoptera: Ichneumonoidea). Zool. Verh. Leiden 283: 1-189.

ACHTERBERG, C. VAN \& A.D. Austin. 1992. Revision of the genera of the subfamily Sigalphinae (Hymenoptera: Braconidae), including a revision of the Australian species. Zool. Verh. Leiden 280: 1-44.

CHEN, X. \& J. HE. 1992. The genus Acampsis Wesmael from China (Hymenoptera: Braconidae: Sigalphinae). Entomotaxonomia 14 (3): 217-222.

Recebido em 30.VIII.1995; aceito em 19.VIII.1996. 